\title{
Simulation and Numerical Modeling of Mechanical Properties of Stainless Steel Mold X39CrMo17- 1
}

Bouklouche Issam, Younes Rassim*, Idir Abdelhek, Bradai Mohand Amokrane, Sadeddine Abdelhamid

Laboratory of Mechanics, Materials and Energetics (L2ME), Faculty of Technology, University of Bejaia, Bejaia 06000, Algeria

Corresponding Author Email: issam.bouklouche@univ-bejaia.dz

https://doi.org/10.18280/rcma.290602

Received: 8 September 2019

Accepted: 14 November 2019

\section{Keywords:}

injection machine, stainless steel, mechanical properties, thermodynamic properties

\begin{abstract}
This paper designs two molds based on stainless steel X39CrMo17-1, and studies their thermo-mechanical behavior through finite-element simulation on SolidWorks. Based on the simulation results, detailed analysis was carried out on the following aspects: the fluid distribution on the edge of each mode in a hot blowing cycle, the temperature distribution during the injection of thermoplastics, as well as the mechanical properties like deformation and stress resistances. The results show that, the two molds had no significant difference in air flow behavior at 30 bars; the variation of the airflow velocity field was less pronounced on the inner wall; the thermal stress was homogenous in both molds; the drawing rate on the inner wall was much higher than that on the outer wall; the two molds had no significant elastic deformation under $150 \mathrm{kN}$. Overall, the designed molds can keep the crystallization temperatures of the polyethylene terephthalate (PET).
\end{abstract}

\section{INTRODUCTION}

Since the invention of the first machine in 1872 by brothers John and Tsiah Hyatt [1], injection molding is the most commonly used process industrially for shaping thermoplastics, and even thermosetting, of all the types of finished objects [2]. An injection-molding machine consists of a plasticizing unit, a clamping unit (in which the mold is fixed) and a control unit. This process is used to manufacture hollow bodies. This perform is then hot deformed by an air jet and pressed against the walls of the mold, it can be manufactured by extrusion (extrusion blow molding) or by injection (injection blow molding) [3]. The injection mould is one of the essential parts that fill many functions, in particular that of giving the raw material a final shape [4].

The materials used for the manufacture of thermoplastic injection molds are mainly steels selected according to the manufacturing process adopted for the mold and the conditions of use (solicitations, interactions with polymers...). The increase of mechanical properties results in the addition of alloying elements which can be harmful. Stainless steels play a high role in large areas: Mechanical industry, agribusiness, chemistry, medicine...etc. [5-8].

This work is based on a numerical modeling and simulation of mechanical properties of a mold in stainless steel $\mathrm{X} 39 \mathrm{CrMo17}-1$. This study is carried out by simulation software SolidWorks, and the various tests performed during the simulation are: Study of the distribution of the fluid during a hot blowing cycle, thermal study during the operation of a mold, study of mechanical properties such as the resistance to deformation and supported stress.

Throughout the main text, please follow these prescribed settings: 1) the font is mostly Times New Roman; 2) almost all the words are typed in 10 points; 3 ) each line throughout the paper is single-spaced; 4) in most cases, 10 pts spacing shall be left above and below any heading, title, caption, formula equation, figure and table.

As mentioned in the abstract section, it will be rather easy to follow these rules as long as you just replace the "content" here without modifying the "form".

\section{STUDY AND DESIGN}

A mold is composed of 2 distinct parts, a moving part and a fixed part. These names are made according to their uses on an injection molding machine. The fixed part is the molded nozzle does not move. She will be in contact with the bridge during each cycle. The mobile part, or being located at the ejection, will be subject to a displacement in translation, from their nominations.

\subsection{Design and sizing of molds and bottles ( 01 and 02 liters)}

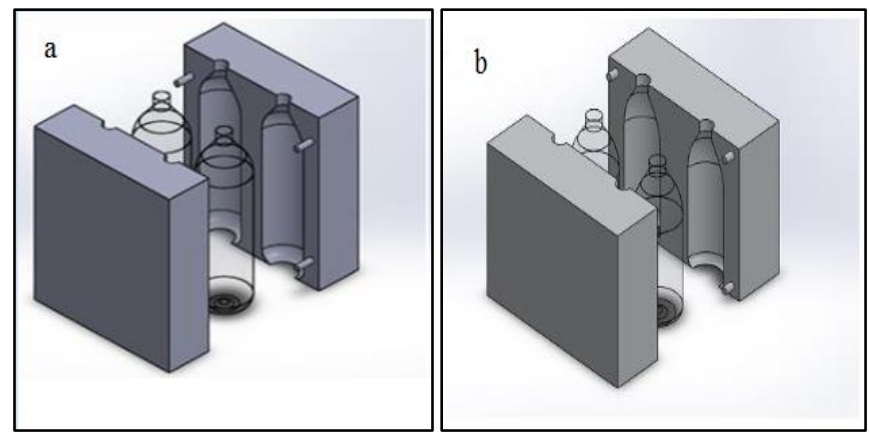

Figure 1. Models 3D from SolidWorks software (a) Double cavity mold 02 liters, (b) Double cavity mold 01 liter

The Figure 1 shows a view 3D of the both models (01 and 
02 liter molds) designed using SolidWorks software. To do this, we started with the geometry of the part in 2Dusing the sketch tools, then creating the volume to generate the model in 3D. Indeed, the material used in this study is a stainless steel type X39CrMo17-1 for both molds (Figure 1) and polyethylene terephthalate for bottles (Figure 2). Our molds have a parallelepiped shape with two imprints composed of two symmetrical parts. The dimensions of each part of the two molds are shown in Table 1.

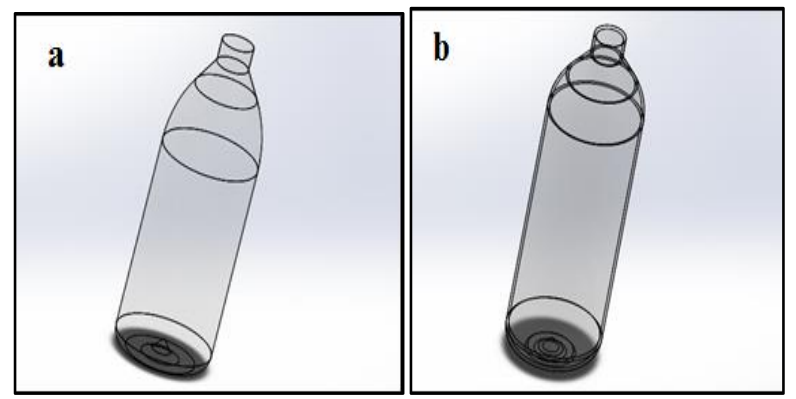

Figure 2. Geometric models of the two bottles a) Bottle 1 liter, b) Bottle 2 liter

Table 1. Dimensions of the mold 01 liter

\begin{tabular}{ccc}
\hline Dimensions & Mold 1 L & Mold 2 L \\
\hline Length & $270 \mathrm{~mm}$ & $320 \mathrm{~mm}$ \\
Width & $265 \mathrm{~mm}$ & $280 \mathrm{~mm}$ \\
Thickness & $80 \mathrm{~mm}$ & $80 \mathrm{~mm}$ \\
Distance between the two imprints & $24 \mathrm{~mm}$ & $18 \mathrm{~mm}$ \\
Distance between the imprint and & $34 \mathrm{~mm}$ & $53 \mathrm{~mm}$ \\
the edge & $74 \mathrm{~mm}$ & $82,5 \mathrm{~mm}$ \\
Diameter of the imprint & $19 \mathrm{~mm}$ & $22 \mathrm{~mm}$ \\
Diameter of the neck & & \\
\hline
\end{tabular}

\subsection{Thermo-mechanical behavior of the two molds}

\subsubsection{Thermal behavior of blowing}

The thermal behavior of the different geometric models has been studied. This last consists of injecting compressed air into the volume at a temperature of $80{ }^{\circ} \mathrm{C}$ and under pressure of 30 bars. In addition, a triangular mesh type was chosen to follow the evolution of the distribution of the airflow on each point of the surface of the inner walls of the various molds.

\subsubsection{Mechanical behavior of the different molds}

The development of computer techniques has allowed a massive use of modeling tools for the design and production of manufactured products. In this context, the mechanical behavior of the different molds has been studied, with the aim of quantifying their mechanical resistance. To do this, a compression test on a pressure force of $150 \mathrm{KN}$ was carried out as industrial practices. Simulation model was established through the analysis on relevant constraints, such as Von Mises strain and deformations.

\section{RESULTS AND DISCUSSION}

\subsection{Thermal behavior of blowing}

Figure 3 illustrates the behavior of the fluid that compressed air in the different molds 01 and 02 liters respectively.

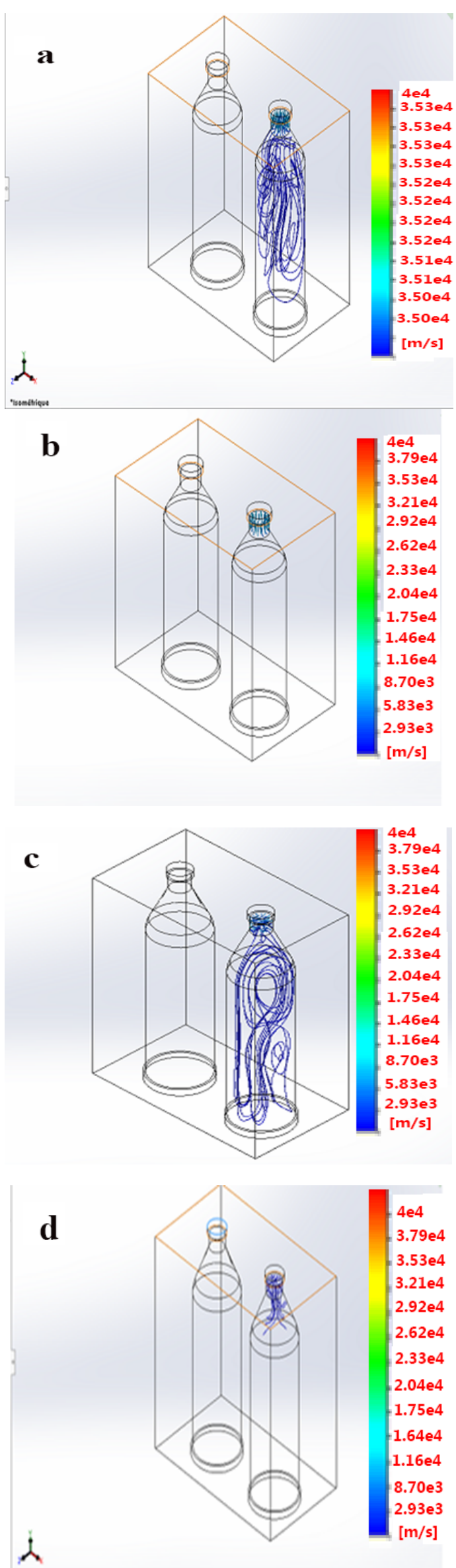

Figure 3. Fluid behavior in the different molds 01 (a-b) and 02 (c-d) liter, a-c) air injection, b-d) air depressurization 
Through its results, the injection of the air flow under a pressure of 30 bars, resulted in the distribution of the latter over all the volume occupied by perform (bottle 01) as shown in (Figure 3a). As a result, it is clearly visible that the distribution of the concentric velocity fields was found to be greater than that distributed along the perimeter.

So that the injection of air fills all the cavity of the mould, there is a turbulent movement of the fluid which is translated as a depressurization air flow as shown in (Figure 3-a-c). Therefore, the speed and depression at seems to change from about $401,560 \mathrm{~m} /$ and 29 bars respectively under a temperature of $293,20 \mathrm{~K}$. Through these results we note no significant difference in the behavior of the air flow of the two molds, in other words, the air velocity and depression look very similar in different molds (401,560 m / and 29 bars). This is very interesting, the same output speed caused relevant point of adhesion of PET film with stainless steel mold [9-12].

However, the thermal behavior of the internal cavities of the different molds 01 and 02 liters respectively as shown in Figure 4. Indeed, the blue color means that a zone is less deformed against the red color means the most deformed area. As a result, the injection of an area flow under a temperature of $353 \mathrm{~K}$ resulted in a homogeneous thermal distribution of stresses in all the volume occupied by the different molds 01 and 02 liters respectively.

Figure 5 shows the variation of the temperature of the perform as a function of time. To do this, the distribution of the heat flux was studied around a point located at a distance of $40 \mathrm{~mm}$ from the thread (point corresponds to the median node of the mesh). The temperature variation increases linearly as time increases. There is a good agreement between the external temperatures predicted numerically at the end of the heating phase the error on the temperature is less than $5 \%$. In addition, we can see that after $3 \mathrm{~s}$ of maintenance, the internal temperature of the perform becomes higher than the external temperature. This phenomenon of temperature inversion is due to the fact that the outer wall of perform is, while the diffusion of heat in the thickness of perform tends to increase the temperature of the inner face.

We can note also from draw ratio (ratio between the initial radius and the final radius) at the inner wall of the perform is much greater than that of the outer wall. Consequently, the stresses induced during the shaping appear higher beings at the level of the internal wall. Its probably due to of conduction between a surface of outer perform (PET) and the surfaces of mould.
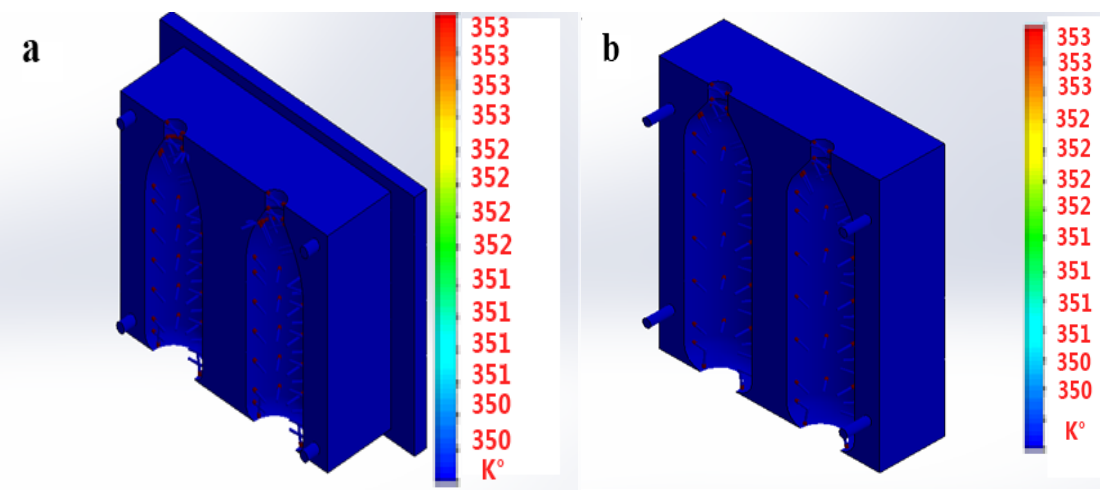

Figure 4. Distribution of thermal stresses of the model deferent Mold 01 liter. b) Mold 02 liters

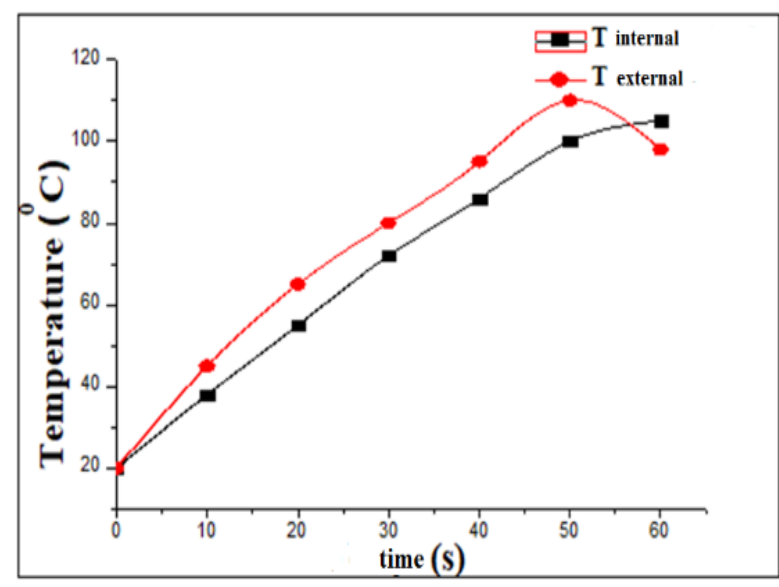

Figure 5. Variation of the temperature as a function of time

\subsection{Mechanical behavior of the molds 01 and 02 liter}

\subsubsection{Mechanical behavior of the mold (01 liter)}

From the simulation keep on figure 6 , the results reveal that the minimum and maximum stress distribution varied in the order of $2.225 .104 \mathrm{~N} / \mathrm{m}^{2}$ and $3.27 .106 \mathrm{~N} / \mathrm{m}^{2}$ respectively. Its show also two area the first with low stress and deformation is in the molds, whereas, the high stress is applied in the top of mold, As an explanation, it can be concluded that the various molds produced have a large tolerance range, which justifies the latter having a high resistance under applied pressure reach $(150 \mathrm{KN})$. While the maximum deformation distribution changes at $4.938 * 10-4 \mathrm{~mm}$. this value of deformation which occur on the top of mould (red area figure 6-b) is still in the elastic domain of the material [13-16].

\subsubsection{Mechanical behavior of the mold (02 liter)}

The evolution of the minimum and maximum stress distribution according to Von Mises is depicted on Figure 7-a. the stress values varies from $1.693 .10^{3} \mathrm{~N} / \mathrm{m}^{2}$ to $3.405 .10^{6} \mathrm{~N} / \mathrm{m}^{2}$. However, it is noted that the maximum stress always remains below the elastic limit of the material X39CrMo17-1 $\left(3.405 .10^{6} \mathrm{~N} / \mathrm{m}^{2}<6.10^{8} \mathrm{~N} / \mathrm{m}^{2}\right)$. While the maximum of deformation on the top of mold was recorded is $4,922 * 10^{-4} \mathrm{~mm}$. A very similar behavior of the distribution and deformations displacements under compressive stress of the different molds $4.938^{*} 10^{-4} \mathrm{~mm}$ and $4.922 * 10^{-4} \mathrm{~mm}$. We note also the materials $\mathrm{X} 39 \mathrm{CrMo17}-1$ and the new geometry is available for made the new mold of 2 liter, this concept mold of X39CrMo17-1 present a higher mechanical resistance than first mold and same thermodynamic properties. 

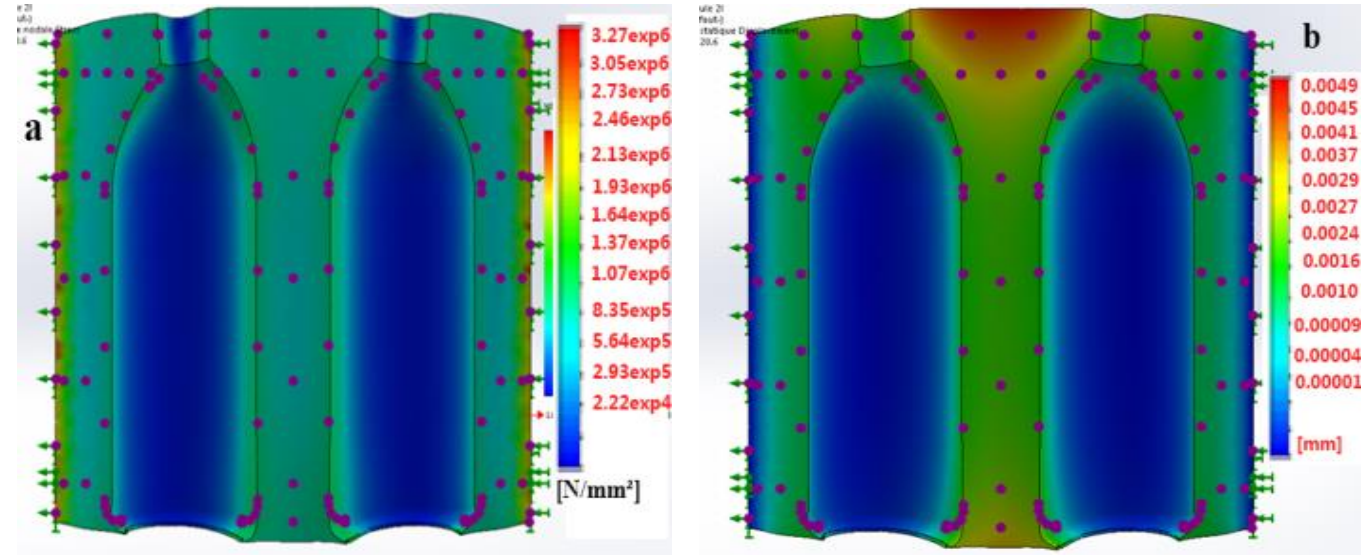

Figure 6. Mechanical stress distribution of different molds a) Von mises stress, b) Distribution of deformations
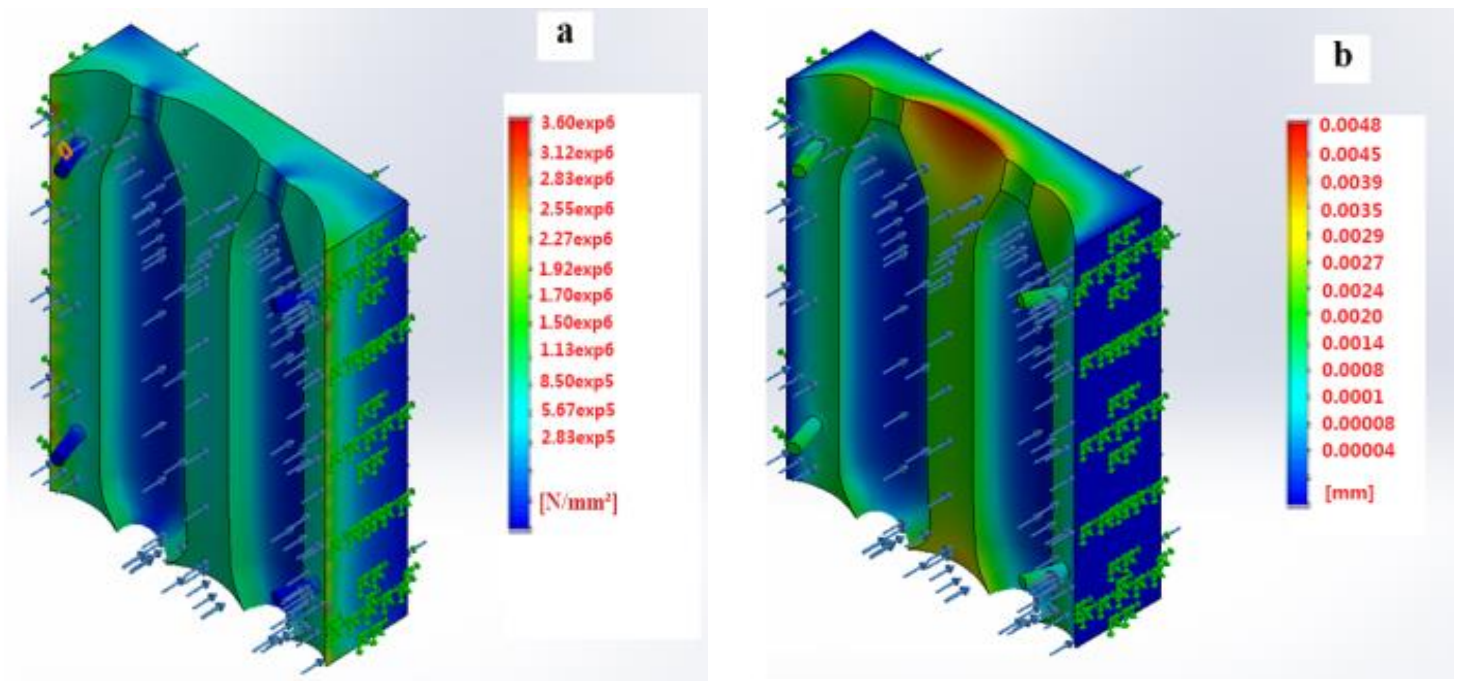

Figure 7. Mechanical behavior of the mold 02L a) Von mises stress, b) Distribution of deformations

\section{CONCLUSIONS}

The purpose of this works is to study of design and dimensioning of two molds to see 01 and 02 liters. The thermo-mechanical behavior of different molds was studied by the finite element method using SolidWorks software, the main results obtained indicating:

- No significant difference of the air flow behavior in both molds at a pressure of 30 bars.

- The variation of the airflow velocity fields was less pronounced on the inner walls of the perform.

- The distribution of thermal stresses homogeneous in all the volume occupied by the different molds ( 01 and 02 liters).

-The drawing rate (ratio between the initial radius and the final radius) on the inner wall of the perform is much higher than that on the outer wall.

- No significant deformation of the elastic deformations of the different molds under a load of $150 \mathrm{KN}$.

\section{RECOMMENDATIONS}

For more investigation for this study some works complementary aspects seem necessary as:

(1) Non-local volume approach to take into account the effect and the presence of geometric defects on the fatigue behavior.
(2) Study the parameters of electrochemical impedance measurements linking the amount of surface (locally exposed) by cyclic mechanical loading.

(3) Technological study and feasibility implementation of a machining process of a digital model four perform on mold.

\section{REFERENCES}

[1] Mael, M. (2005). Development of a tool to assist in the Design and operation of an industrial screw /sheath assembly-application to the injection of thermoplastics loaded with long glass. Ph.D. dissertation. The National Institute of Applied Sciences of Lyon, Lyon, France.

[2] Rosato, D.V., Etrosato, M.G. (2000). Injection Molding Handbook. Boston/Dordrecht/London, Kluwer Academic Publishers.

[3] Mohamed, R., Jean-Marie, R., Jean-Louis, B. (1994) Numerical simulation of blowing and thermoforming of plastics. European Review of Elements, 3(2): 187-210.

[4] Rubin, I.I. (1972). Injection Molding Theory and Practice. New York, London, Sydney, Toronto, John Wiley and Sons.

[5] Lacombe, P., Baroux, B., Beranger, G. (1984). Stainless Steels - Editions of Physics. Scientific Publishers.

[6] Chen, X.C., Guan, J.F., Deng, S.S., Liu, Q., Chen, M. (2018). Features and mechanism of abrasive water jet 
cutting of Q345 steel. Revue des Composites et des Matériaux Avancés, 36(1): 81-87. https://doi.org/10.18280/ijht.360111

[7] Zhang, Y.X., Zhang, Y.L. (2018) Characteristics analysis of mechanical seal face based on thermo-hydrodynamic effect. Revue des Composites et des Matériaux Avancés, 36(3): 1025-1030. https://doi.org/10.18280/ijht.360332

[8] Du, H.W., Xiong, W., Wang, H.T., Wang, Z.W. (2017). Physical modeling and deformation simulation of flexible cable under the plane constraint. Journal Européen des Systèmes Automatisés, 50(4-6): 471-484. https://doi.org/10.3166/JESA.50.471-484

[9] Wang, W.T., Feng, B.Y. (2019). Mechanical behavior and reliability of anchoring resin under thermomechanical coupling. Revue des Composites et des Matériaux Avancés, 37(2): 466-470. https://doi.org/10.18280/ijht.370212

[10] Mouadji, Y., Amokrane, B.M., Younes, R., Sad-eddine, A., Benabbas, A. (2018). Influence of heat treatment on microstructure and tribological properties of flame spraying Fe-Ni-Al alloy coating. Journal of Central South University, 25(3): 473-481. https://doi.org/10.1007/s11771-018-3751-6

[11] Mukhtar, S., Asghar, W., Butt, Z., Abbas, Z., Ullah, M., ur Rehman, R.A. (2018). Development and characterization of hot dip aluminide coated stainless steel 316L. Journal of Central South University, 25(11): 2578-2588. https://doi.org/10.1007/s11771-018-3937-y
[12] Nie, Z.G., Wang, G., Jiang, F., Lin, Y.L., Rong, Y.M. (2018). Investigation of modeling on single grit grinding for martensitic stainless steel. Journal of Central South University, 25(8): 1862-1869.

[13] Mansouri, K., Djebaili, H., Brioua, M. (2017). The influence of fiber arrangement on the mechanical properties of short fiber reinforced thermoplastic matrix composite. Revue des Composites et des Matériaux Avancés, 27(3-4): 261-274. https://doi.org/10.3166/rcma.2017.00027

[14] Achour, T., El Euch Khay, S., Jarraya, E., Neji, J. (2017). Combined contribution of experiments and modeling to better understand mechanical properties of concrete. Revue des Composites et des Matériaux Avancés, 27(12): 123-136. https://doi.org/10.3166/rcma.2017.00008

[15] Musazadeh, M.H., Vafaei, R., Sharifi, E.M., Farmanesh, K. (2018). Mechanical properties, microstructural evolution, and the effect of friction on the plastic flow of the AISI 321 austenitic stainless steel tube during cold pilgering: An experimental and simulation analysis. Metallurgical and Materials Transactions B, 49(6): 30303042.

[16] Narayanareddy, V.V., Chandrasekhar, N., Vasudevan, M., Muthukumaran, S., Vasantharaja, P. (2016). Numerical simulation and artificial neural network modeling for predicting welding-induced distortion in butt-welded 304L stainless steel plates. Metallurgical and Materials Transactions B, 47(1): 702-713. 